\title{
¿Qué factores se asocian a la violencia psicológica doméstica? Análisis del último decenio de la ENDES
}

\author{
Liset Alarcón-Delgado ${ }^{1}$ \\ Yonathan Ortiz-Montalvo ${ }^{2}$
}

RESUMEN: Objetivo: Determinar la asociación de los factores individuales y de relación de pareja frente a la violencia psicológica en la mujer en los últimos 10 años en el Perú. Metodología: se realizó un análisis secundario de la Encuesta Demográfica y Salud familiar (ENDES) del 2006 hasta el 2015. Para el análisis bivariado se aplicó la prueba de Chi-cuadrado. Del mismo modo se empleó la regresión logística ordinal para calcular Odds Ratio (OR) con intervalos de confianza al 95\%. Así mismo se empleó la prueba de Hosmer y Lemenshow para estimar la bondad de ajuste y las curvas ROC para evaluar la capacidad discriminante de los factores asociados. Resultados: Los principales factores asociados a la violencia psicológica fueron: tener antecedentes de violencia física del padre a la madre (OR: 1.45; IC95\%: 1.35-1.54), ser separada (OR: 4.62; IC95\%: 4.20-5.09) y que las parejas de las mujeres se embriaguen frecuentemente (OR: 12.2; IC95\%: 10.4-14.3). El área bajo la curva de los modelos fueron 0.595 (IC95\%: 0.568-0.632) para los factores individuales y 0.633 (IC95\%: 0.601-0.664) para los de relaciones de pareja. Conclusiones: Los factores sobre la relación de pareja (ser separadas, embriaguez frecuente de la pareja y casarse por primera vez en edad adolescente) aumenta la posibilidad de ser víctimas de violencia psicológica. Mientras que ser casada, pertenecer a un índice de riqueza alto y tener una educación superior disminuyen dicho fenómeno.

PALABRAS CLAVE: Citar como:
Violencia de pareja; Abuso psicológico; Mujeres.

Alarcón L, Ortiz Y. Factores asociados a la violencia psicológica en la mujer peruana en los últimos 10 años. CASUS. 2017;2(1):11-27.

\footnotetext{
${ }^{1}$ Universidad Católica Sedes Sapientiae. Estudiante de psicología. 2Universidad Católica Sedes Sapientiae. Licenciado en enfermería. 


\section{INTRODUCCIÓN}

La violencia contra la mujer por parte de su pareja es un problema social que afecta la salud pública debido a la magnitud y consecuencias que esta ha alcanzado en los últimos años. Estas consecuencias suelen ser irreversibles tanto en el ámbito personal, familiar y social de la víctima. Asimismo, esta es una materia de discusión dentro de las políticas en los diferentes países del mundo $(1,2)$. La Organización Mundial de la Salud (OMS) indica que la prevalencia mundial de violencia contra la mujer se da en una de cada tres mujeres (3). Contra la mujer no solo se ejerce violencia física, sino que existen otros tipos como es el caso de la violencia psicológica. Que puede anteceder a la violencia física (4).

Actualmente en el Perú el 67.4\% de las mujeres sufre de violencia psicológica (5). Este tipo de violencia afecta directamente la salud mental de la mujer y su estado emocional. Asimismo entre sus consecuencias destacan el aislamiento social, la baja autoestima, la dependencia de la pareja y la falta de seguridad (6). Estos elementos evidencian la vulnerabilidad de la mujer frente a su agresor (6).

La violencia psicológica se define como la agresión a través de palabras, gritos, insultos, situaciones de control, humillaciones, amenazas y otras acciones para aminorar la autoestima de la persona $(1,3)$. Esta se asocia a la condición económica, al ámbito geográfico y al nivel educativo de la mujer (7). La literatura manifiesta que existen características individuales de la mujer que se relacionan con una mayor probabilidad de ser violentadas psicológicamente. Principalmente se puede originar en las mujeres con recursos económicos o niveles educativos bajos $(8,9)$. Del mismo modo estas mujeres viven generalmente en áreas geográficas sometidas a normas culturales en las que se cree que los hombres tienen el derecho a ejercer maltrato contra la mujer (10). Se debe también tener en cuenta que un predictor de la violencia psicológica es presenciar maltrato físico de la madre por parte del padre $(11,12)$.

Cabe resaltar que no solo las características personales de la mujer influyen en la violencia psicológica sino que también se deben tomar en cuenta las características en relación a la pareja. Muchas mujeres piensan que al separarse de su pareja estarían menos expuestas a ser violentadas que aquellas que conviven con su agresor. Por el contrario, esta situación no garantiza la seguridad de la víctima e incluso podría agravarse (13). Otra característica importante de la pareja es el excesivo consumo de alcohol. El mismo afecta la salud mental de la persona trayendo consigo comportamientos negativos contra los más cercanos en el hogar, en particular su pareja (14). Igualmente el control que los hombres ejercen en sus hogares sin tener consideración la toma de decisiones de la mujer contribuye en el inicio de la violencia psicológica (15).

Para construir el marco conceptual de aproximación al problema se consideró la teoría ecológica de Bronfenbrenner y de Heise $(16,17)$. La misma plantea que para entender la violencia es importante tener en cuenta la interacción de los factores sociales, culturales y psicológicos que dan lugar al comportamiento de la víctima y el agresor, para ello es importante conocer los niveles de interacción. Al primer nivel pertenecen las experiencias personales y los factores biológicos, mientras que el segundo se refiere a las relaciones de pareja y familia (18).

Ante la alta prevalencia de la violencia psicológica contra la mujer, sin embargo resulta insuficiente la información acerca de las diferencias de la acción de los factores personales y de pareja respecto a su asociación con la violencia psicológica. Igualmente es escasa la información relativa al comportamiento de estos factores en los últimos diez años. Por esta razón el objetivo del presente estudio fue determinar la asociación de los factores individuales y de relación de pareja con la violencia psicológica en los últimos diez años.

\section{MATERIALES Y MÉTODOS}

Para el estudio se utilizó la base de datos de la Encuesta Demográfica y de Salud Familiar (ENDES) considerando los años 2006 al 2015. La misma fue brindada por el Instituto Nacional de Estadística e Informática (INEI) (19). Las muestras efectivas estuvieron conformadas por mujeres que alguna vez han sufrido violencia psicológica del 2006 hasta el 2015 (ver figura 1). El muestreo fue probabilístico, estratificado y multietápico. Se incluyeron a todas las mujeres entre 15 y 49 años, independientemente si son o no madres de familia. Asimismo se tomó en 
cuenta todas las mujeres que vivían en zonas urbanas y rurales de todos los departamentos del Perú. Para este estudio se excluyeron a las mujeres solteras debido a que no respondieron al módulo de violencia.

Figura 1. Diagrama del tamaño de la muestra por cada año 2006 - 2015

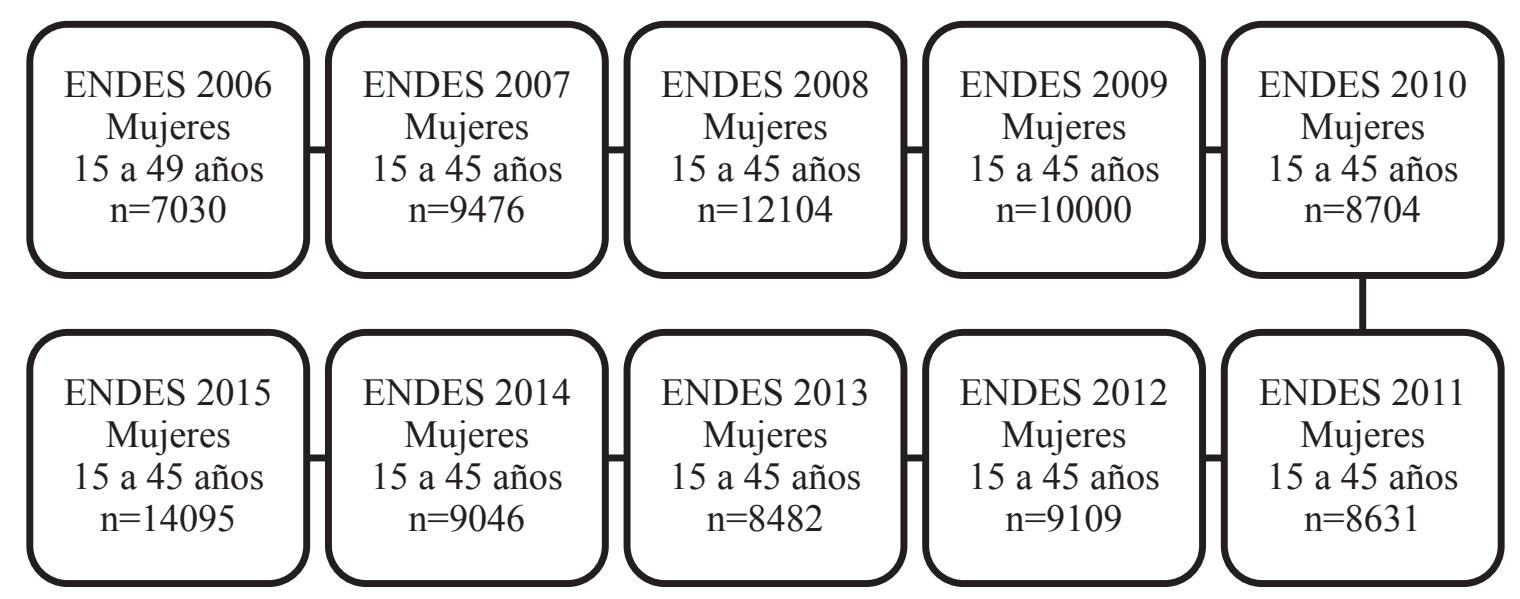

La variable dependiente del estudio fue violencia psicológica, la misma se midió a través de las siguientes preguntas: $¿$ su esposo o marido se pone o se ponía celoso cuando conversa o conversaba con otro hombre?, ¿su esposo la acusa o acusaba de ser infiel?, ¿él le impide o impedía que visite o la visiten sus amistades?, ¿él trata o trataba de limitar las visitas contactos a su familia?, ¿él insiste o insistía siempre en saber todos los lugares donde usted va o iba?, ¿él desconfía o desconfiaba de usted con el dinero?, ¿él le ha dicho o le ha hecho cosas para humillarla delante de los demás?, ¿él le ha amenazado con hacerle daño a usted o a alguien cercano a usted?, iél le ha amenazado con irse de la casa, quitarle a los hijos o la ayuda económica? Para el estudio, la variable se categorizó en sí y no. Asimismo se realizó una categorización para aquellas que han sufrido violencia psicológica en violencia psicológica baja, media y alta.

Para la selección de las variables independientes se tomó en cuenta el modelo ecológico de Bronfenbrenner y de Heise: los factores individuales y las relaciones de pareja. Los factores individuales fueron: edad: variable categórica (15-19, 20-24, 25-29, 30-24, 35-39, 40-44 y 45-49 años); educación de la mujer, variable politómica ordinal (sin educación, primaria, secundaria y superior); residencia, variable dicotómica nominal (urbano y rural); región, variable dicotómica nominal (costa, sierra y selva); antecedente de violencia física del padre a la madre, variable categórica (sí y no). Para categorizar el índice de riqueza: variable ordinal, alto, medio y bajo, se formularon mediante los quintiles de riqueza donde los quintiles inferiores se agruparon en el índice bajo y los dos superiores en el alto, ya que se refieren a los bienes y servicios de la vivienda.

Los factores sobre las relaciones de pareja fueron: estado civil: variable categórica ordinal (convivientes, casadas y separadas); embriaguez de la pareja, variable categórica (nunca, algunas veces y frecuentemente); educación del compañero, variable categórica (sin educación, primaria, secundaria y superior); ha estado alguna vez casada, variable categórica (anteriormente casada o convive con otro hombre); edad al primer matrimonio, variable categórica (10-18, 19-24 y 25-46 años); su pareja toma en cuenta su opinión, originada de la pregunta: ¿su esposo/pareja toma en cuenta su opinión en el hogar?, variable categórica (nunca, a veces y frecuentemente). 
Para la realización del análisis estadístico se empleó el paquete estadístico STATA versión 13. En el análisis univariado de las variables categóricas se calcularon frecuencias y porcentajes. Con respecto al análisis bivariado, se utilizó la prueba de Chi-cuadrado con una significancia estadística menor a 0.05 . Se determinó la fuerza de asociación mediante la regresión logística ordinal, teniendo como resultados los Odds Ratio (OR) e intervalos de confianza al 95\% (IC 95\%). Finalmente se estimó el diagnóstico de regresión de Hosmer-Lemeshow para evaluar el ajuste de los modelos y la capacidad discriminante mediante las curvas ROC, en la que se evaluó el área bajo la curva e intervalo de confianza al $95 \%$.
Los cuestionarios se realizaron de forma anónima por lo que no es posible identificar datos personales de las mujeres. Las encuestadas presentaron un consentimiento verbal para su participación. El presente trabajo fue presentado al Comité de Ética e Investigación de la Universidad Católica Sedes Sapientiae.

\section{RESULTADOS}

En el estudio se muestra que el porcentaje de las mujeres que han sufrido violencia psicológica disminuyó paulatinamente de un $74.1 \%$ en el 2006 a un $65.5 \%$ en el 2015. Sin embargo la violencia psicológica alta se mantiene a través de los 10 años (ver figura 2).

\section{Figura 2. Prevalencia de la violencia psicológica en los últimos diez años}

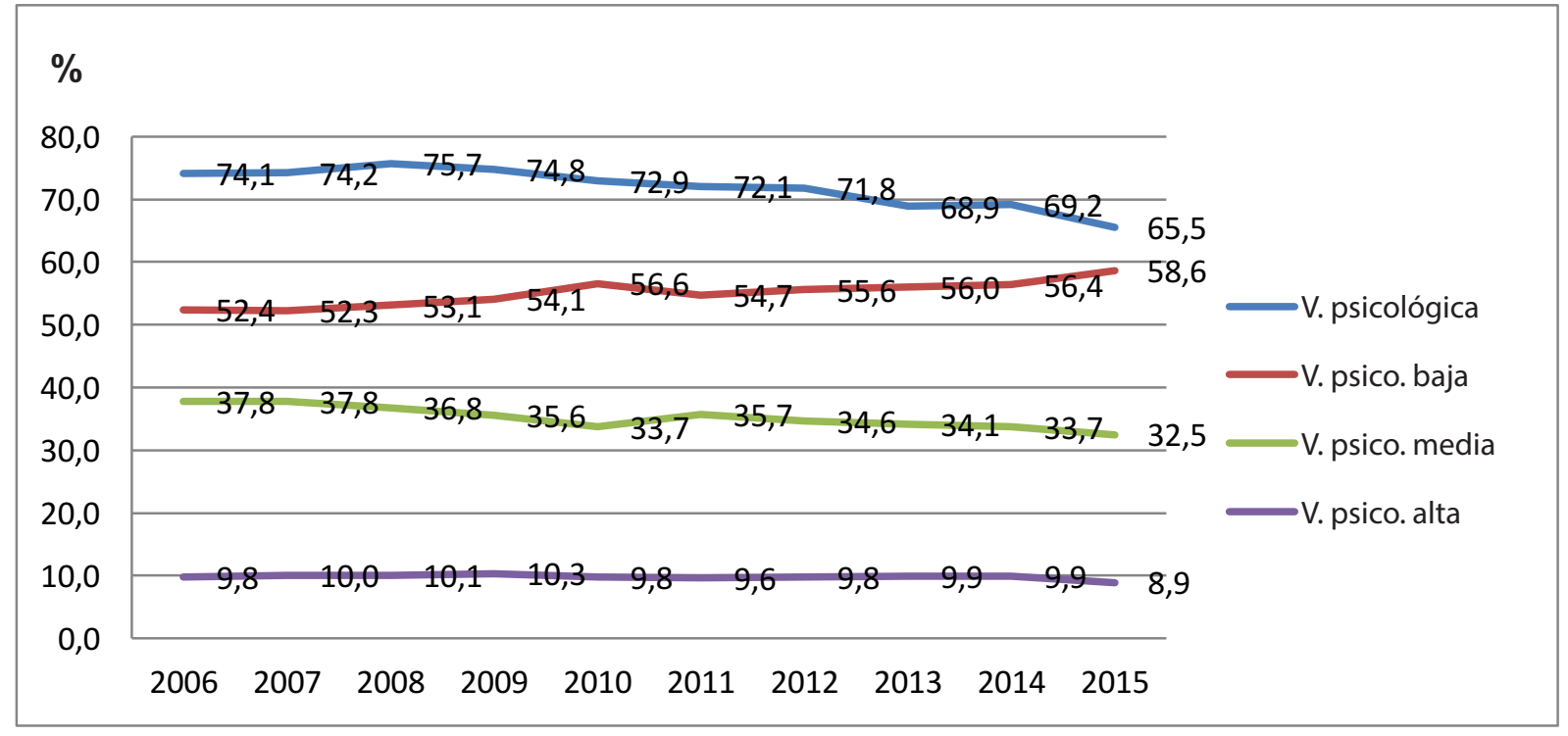

Dentro de los factores individuales se muestra que en el periodo del 2006 al 2015 los porcentajes de las mujeres que vivían en la región costa, las que tenían 30 a 34 años y con educación secundaria aumentaron. Entre los factores de relación de la pareja: la mayoría eran convivientes, las parejas tenían un nivel educativo secundario y frecuentemente la pareja tomaba en cuenta la opinión de la mujer. Estos datos aumentaron porcentualmente a través de los años. El resto de las variables se pueden observar en la tabla 1. 


\begin{tabular}{|c|c|c|c|c|}
\hline 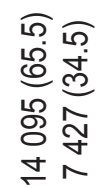 & 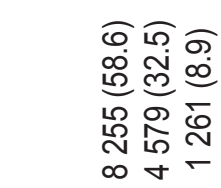 & 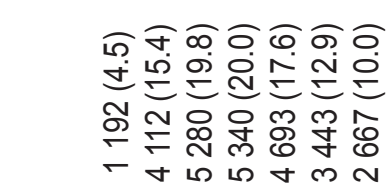 & 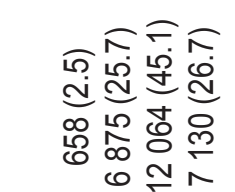 & 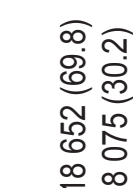 \\
\hline 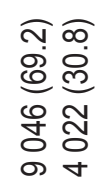 & 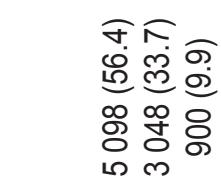 & 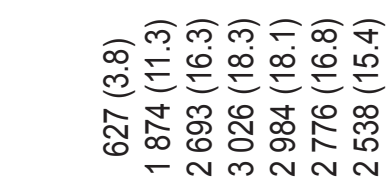 & 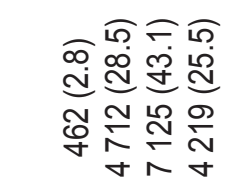 & 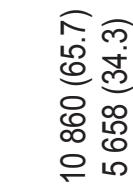 \\
\hline 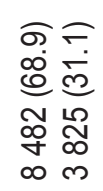 & 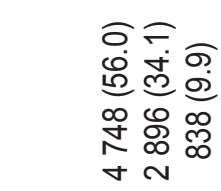 & 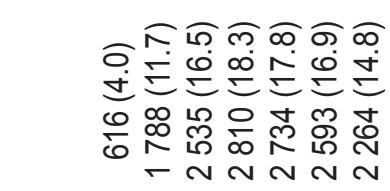 & 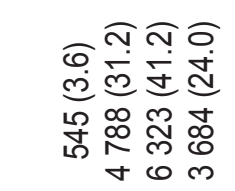 & 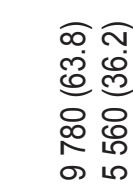 \\
\hline 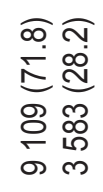 & 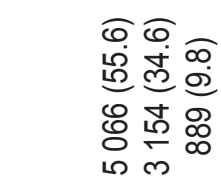 & 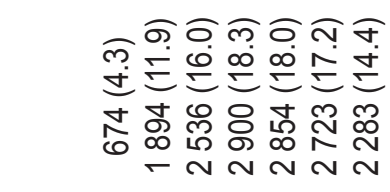 & 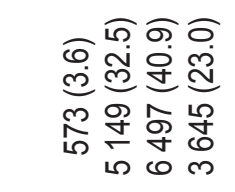 & 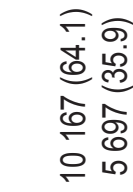 \\
\hline 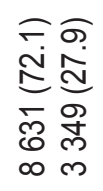 & 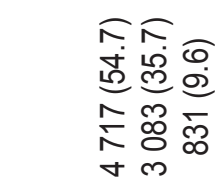 & 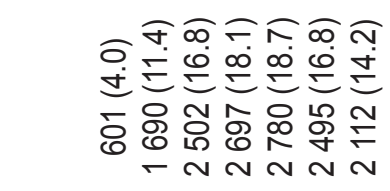 & 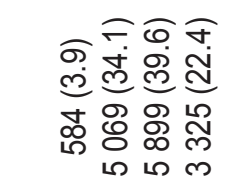 & 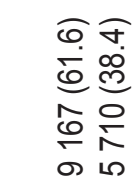 \\
\hline 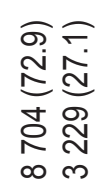 & 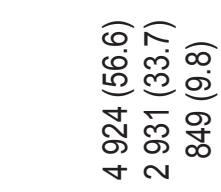 & 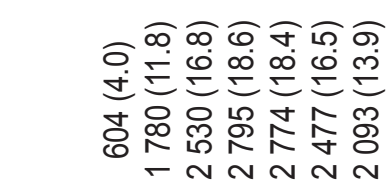 & 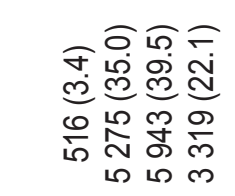 & 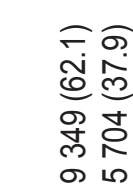 \\
\hline 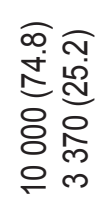 & 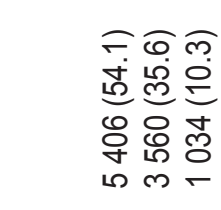 & 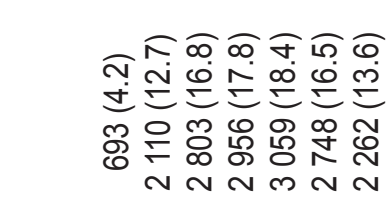 & 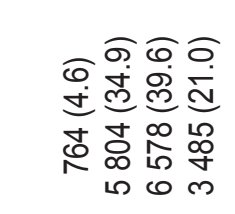 & 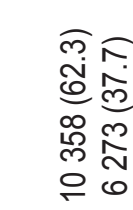 \\
\hline 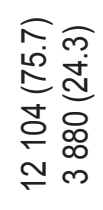 & 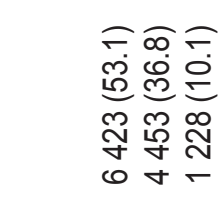 & 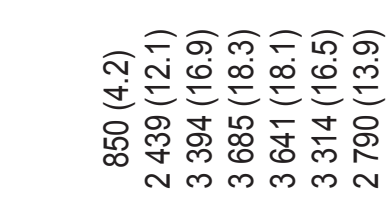 & 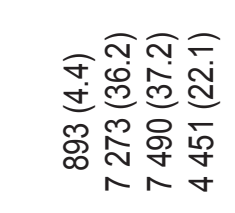 & 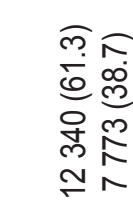 \\
\hline 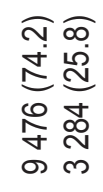 & 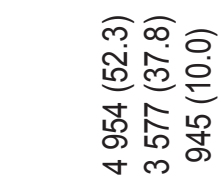 & 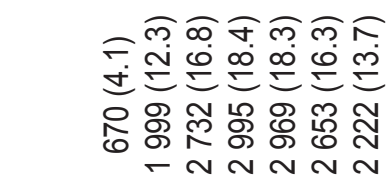 & 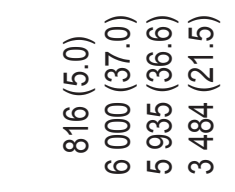 & 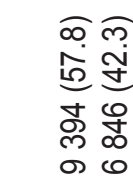 \\
\hline 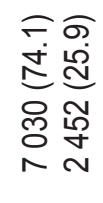 & 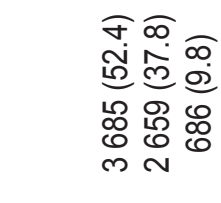 & 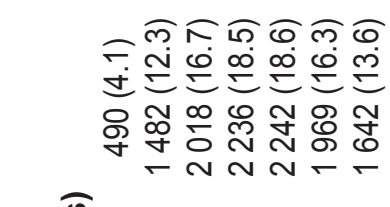 & 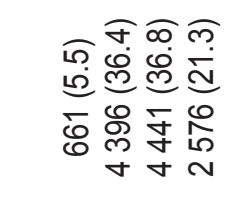 & 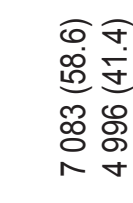 \\
\hline ㅇ & 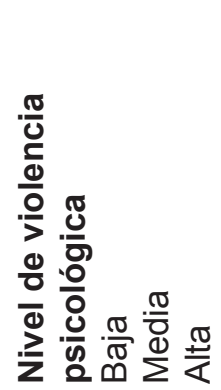 & 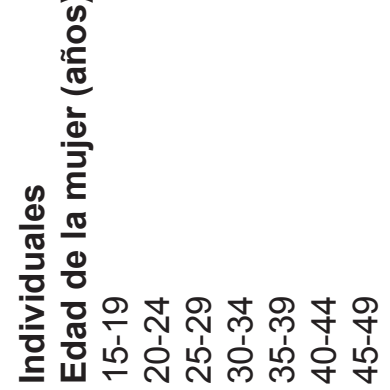 & 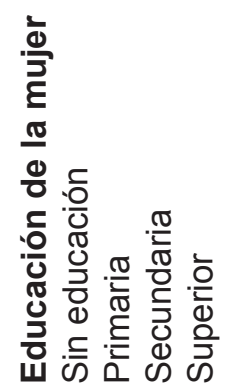 & 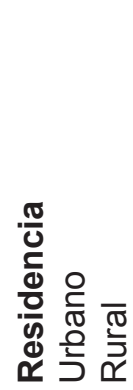 \\
\hline
\end{tabular}




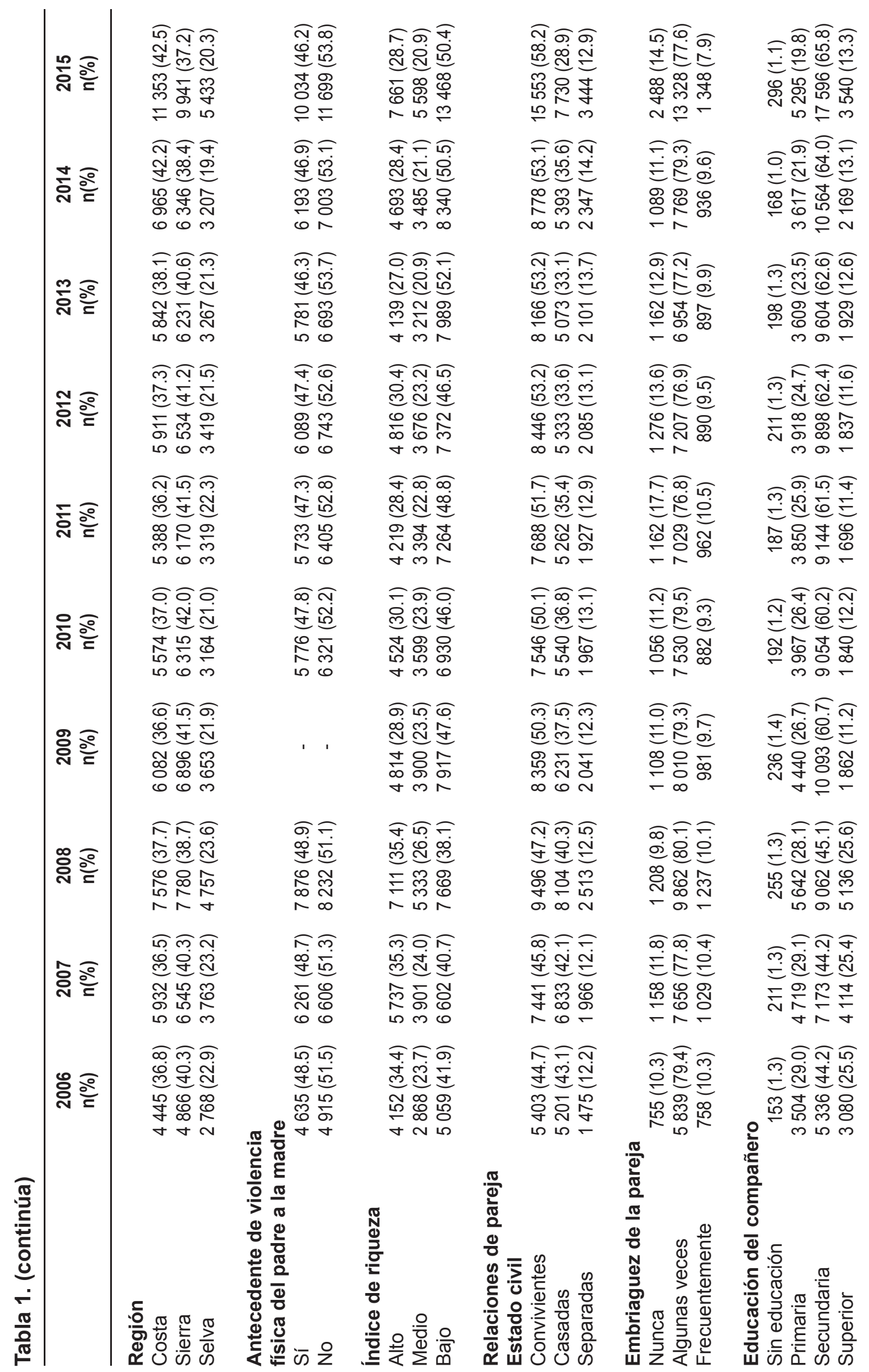




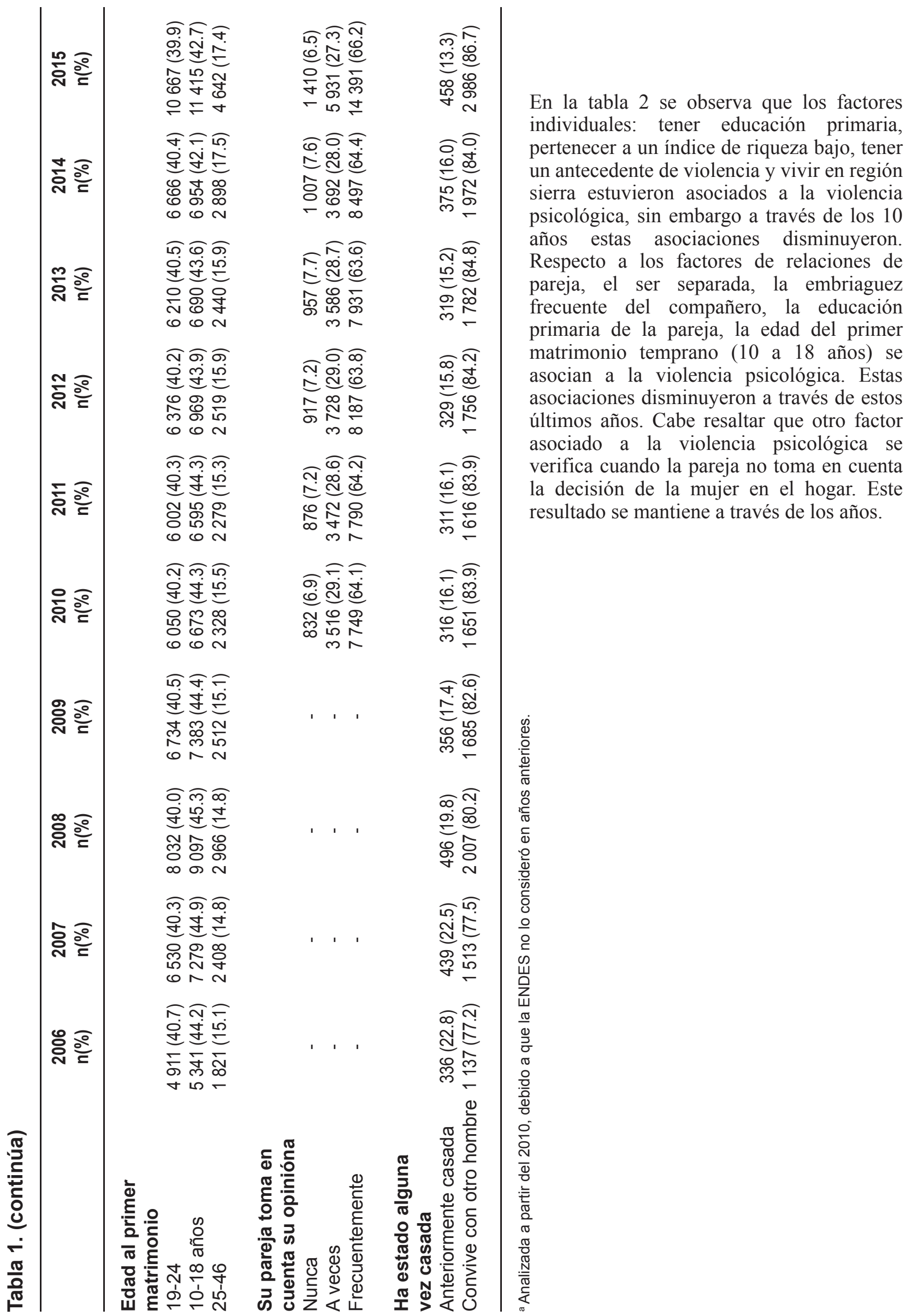




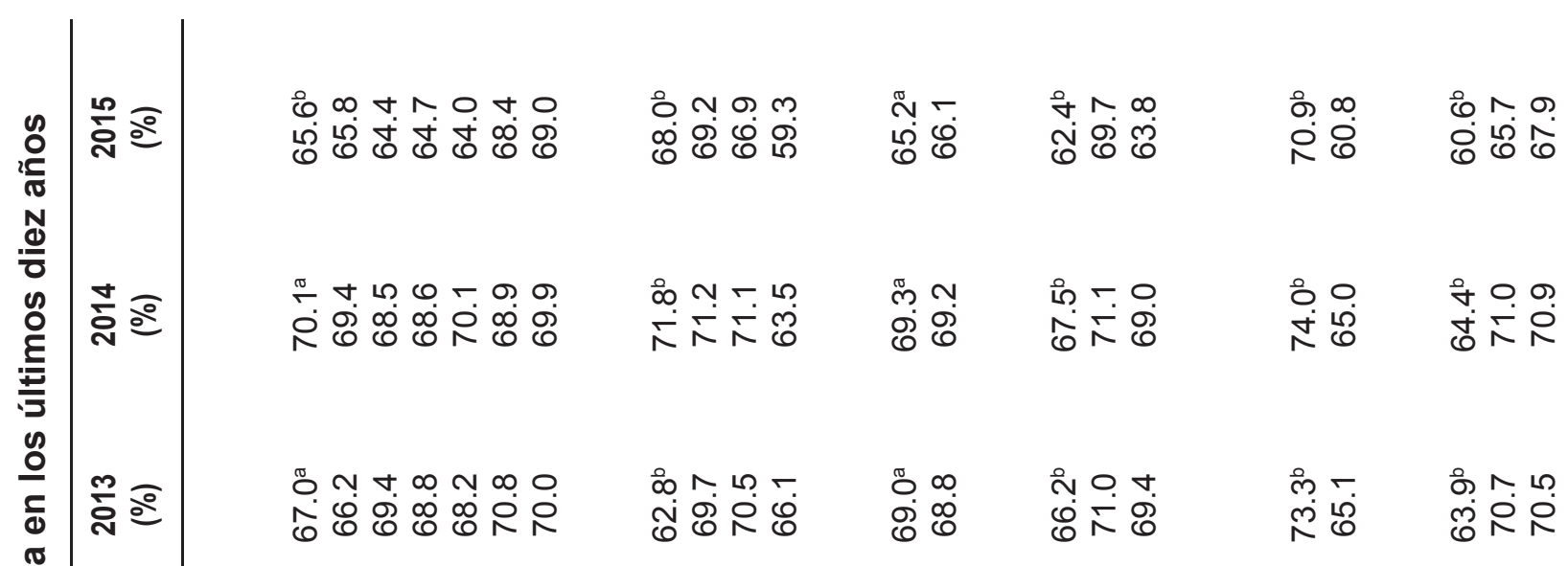

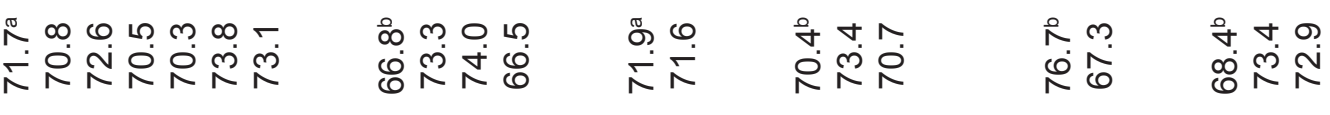

ס

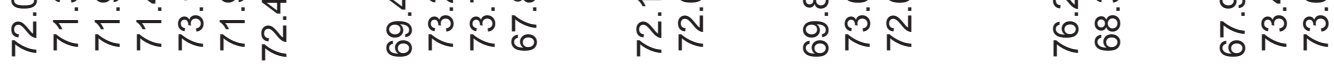

ले m เกำ

$\infty 0,+\infty, \infty \pi$

$\operatorname{Ros} 0$

$\stackrel{5}{\circ}+\frac{1}{2}$

क ก ก

กุด

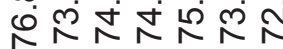

ก๊

ำ

ก็

कำ 눙

กำำ

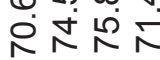

交

六串

कำ ํำ गु 里穴卡
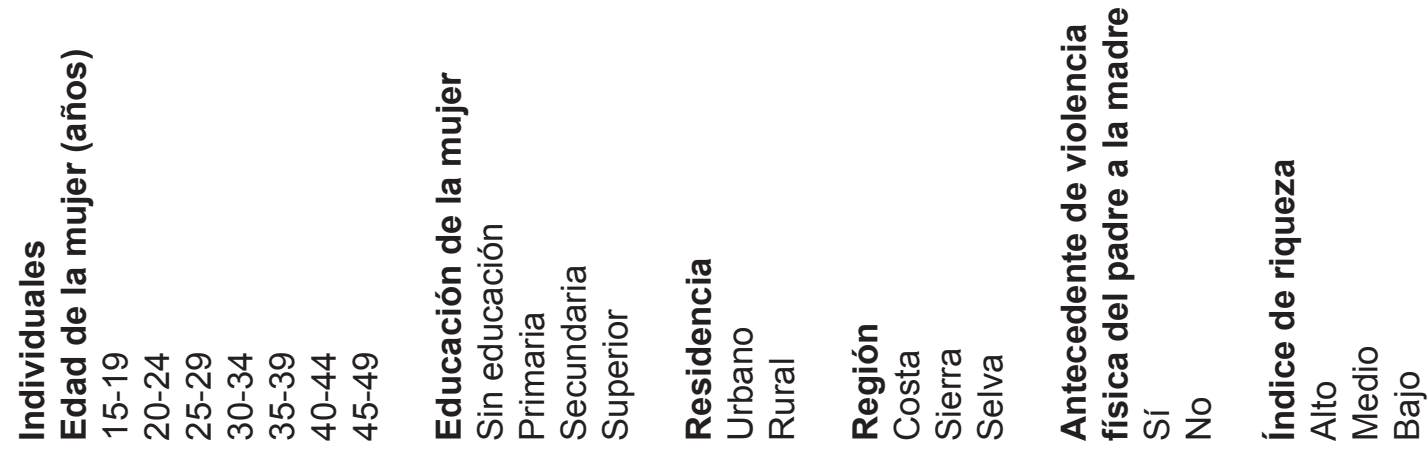


\begin{tabular}{|c|c|c|c|c|c|c|c|c|c|c|}
\hline 눙 & 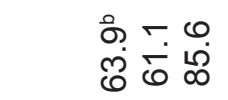 & 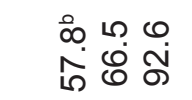 & & 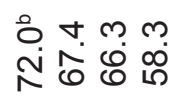 & & 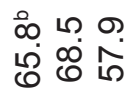 & & 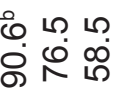 & & 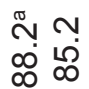 \\
\hline 芯 & 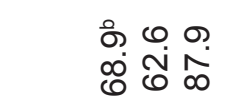 & 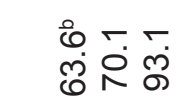 & & 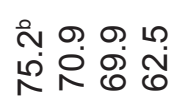 & & 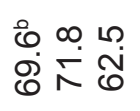 & & 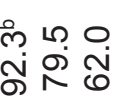 & & $\begin{array}{ll}0 & 0 \\
\infty & 0 \\
\infty & \infty\end{array}$ \\
\hline$\stackrel{m}{\stackrel{2}{a}}$ & $\begin{array}{l}\infty \\
\infty \\
\infty \\
0 \\
0 \\
0\end{array}$ & $\begin{array}{l}\text { mi } \\
\infty \\
\infty\end{array}$ & & 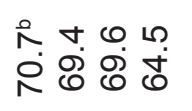 & & 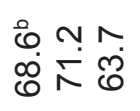 & & $\begin{array}{l}\infty \\
\infty \\
\infty\end{array}$ & & $\begin{array}{l}\text { مَ } \\
\stackrel{\infty}{\infty} \\
\infty \\
\infty\end{array}$ \\
\hline ํํㅇ & 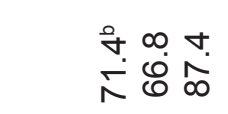 & 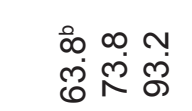 & & 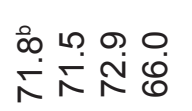 & & 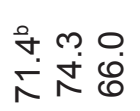 & & 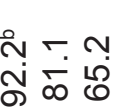 & & $\begin{array}{ll}0 & - \\
\infty & - \\
\infty & \infty\end{array}$ \\
\hline ¿্ণ & 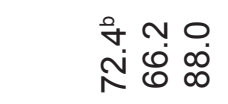 & 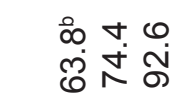 & & 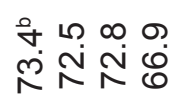 & & 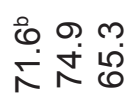 & & $\begin{array}{lll}\infty & 0 & \infty \\
\infty & i & 0 \\
\infty & \infty & 0 \\
\infty\end{array}$ & & 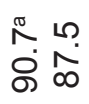 \\
\hline 웅 & 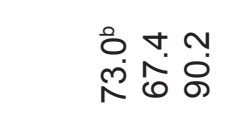 & 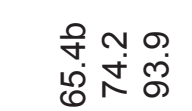 & & 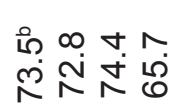 & & 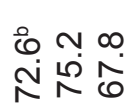 & & $\begin{array}{l}0 \\
0 \\
8 \\
8\end{array}$ & & 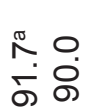 \\
\hline ळे ळ & 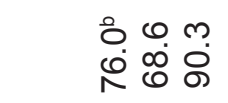 & 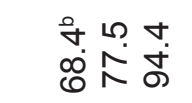 & & 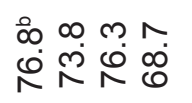 & & $\begin{array}{l}009 \\
\dot{\Gamma}\end{array}$ & & 1 & & ஸ̃ \\
\hline 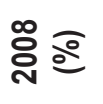 & 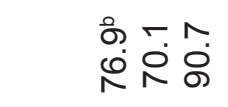 & 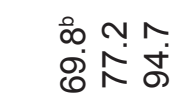 & & 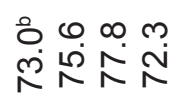 & & 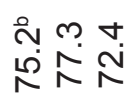 & & 1 & & 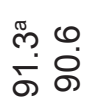 \\
\hline ळ్ㅇ & 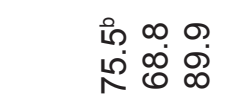 & 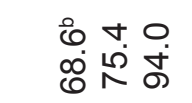 & & 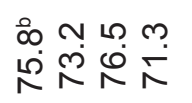 & & 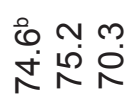 & & ' ' ' & & $\begin{array}{l}\tilde{m} \\
\text { ले } \\
\infty\end{array}$ \\
\hline ¿্సి & 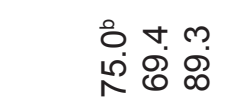 & $\begin{array}{l}R \\
\dot{0} \\
\dot{0}\end{array}$ & & 穴余穴定 & & 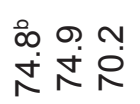 & & 1 & & $\begin{array}{ll}\infty & m \\
\infty & \infty \\
\delta & \infty\end{array}$ \\
\hline & 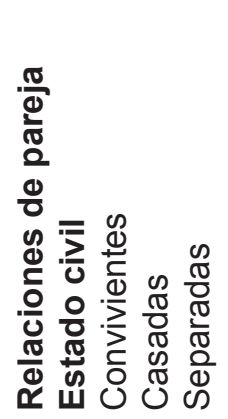 & 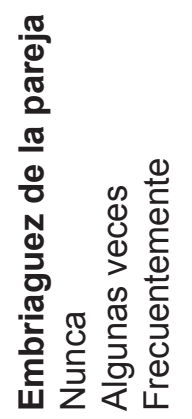 & 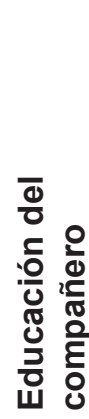 & 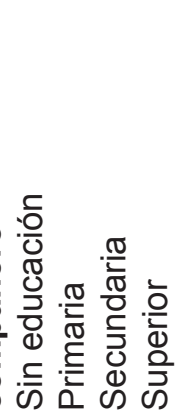 & 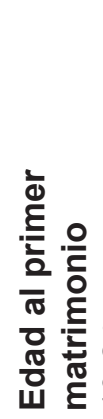 & 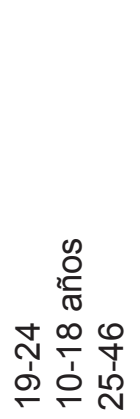 & 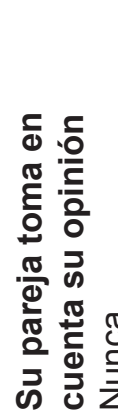 & 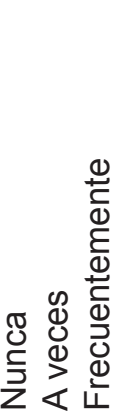 & 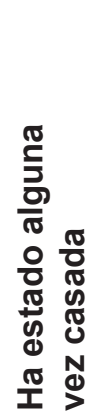 & 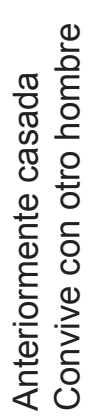 \\
\hline
\end{tabular}


Según los resultados del análisis de regresión logística ordinal se evidenció que vivir en la región sierra se asocia con un aumento a la violencia psicológica en comparación con la región costa (OR: 1.35; IC 95\%:1.26-1.46). Asimismo las mujeres que tenían antecedentes de violencia física del padre a la madre (OR: 1.45: IC 95\%: 1.35-1.54) están expuestas a la violencia psicológica. Respecto a los factores de relación con la pareja, las separadas tenían un mayor riesgo de ser violentadas psicológicamente en comparación con las que eran convivientes (OR: 4.62; IC 95\%: 4.20-5.09). Existe un mayor riesgo de violencia psicológica (OR: 12.2; IC 95\%: 10.4-14.3) donde las parejas de las mujeres se embriagan frecuentemente en comparación con las que nunca lo hacen. Las que se casaban por primera vez y a temprana edad respecto a las se casan a una edad mayor tenían riesgo de ser víctimas de violencia (OR:
1.17; IC 95\%: 1.09-1.25). Los factores protectores fueron: ser casada, tener un índice de riqueza alto, tener una educación superior tanto de la mujer como del hombre, casarse después de los 25 años y tomar en cuenta frecuentemente la opinión de la mujer. Cabe resaltar que los factores: ser separada, tener una pareja que se embriaga frecuentemente, tener antecedentes de violencia física del padre hacia la madre han estado asociados reiteradamente con la violencia psicológica en todos los años analizados (ver tabla 3).

Las bondades de ajuste de los modelos y de cada año indican valores mayores de 0.05 . La capacidad discriminante mediante el área bajo la curva $(\mathrm{ABC})$ fue 0.59 (IC95\%: 0.57-0.63) para los factores individuales y 0.63 (IC95\%: 0.60-0.66) para los de relaciones de pareja. 


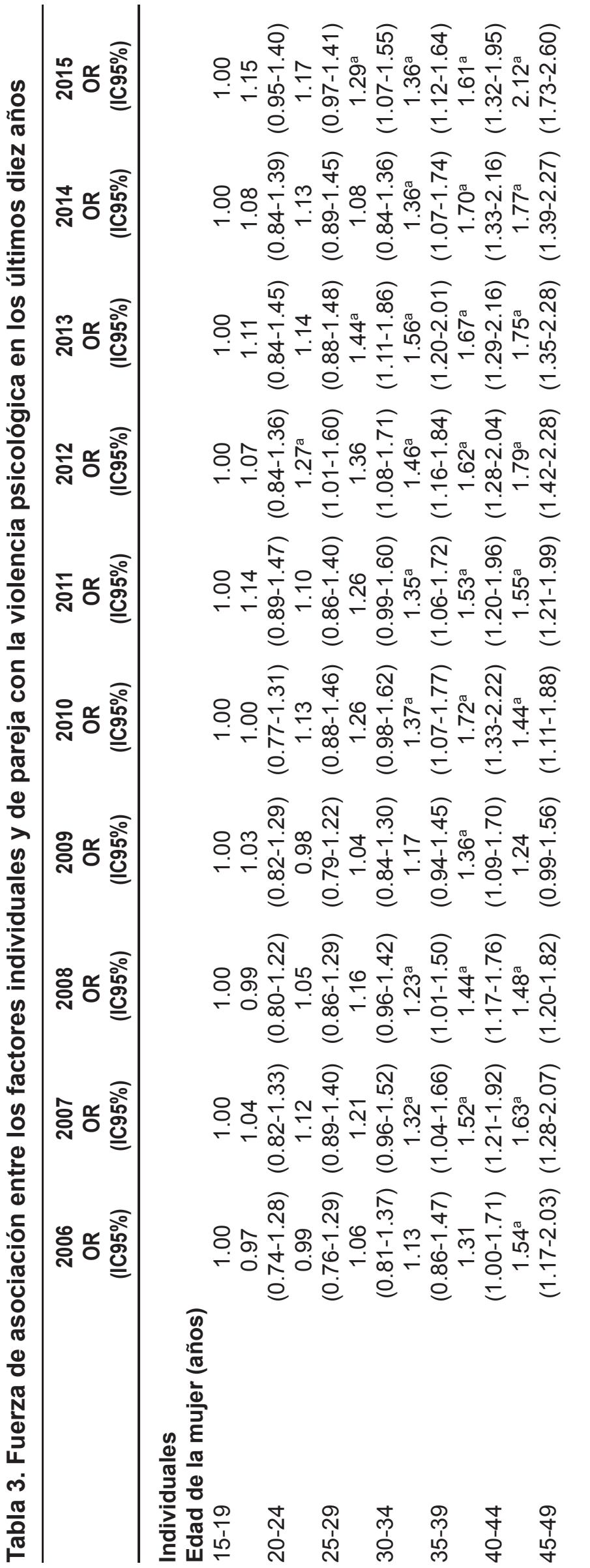

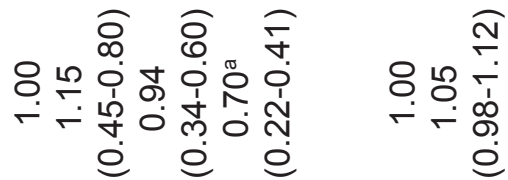

a)

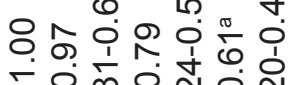

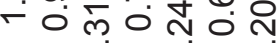

○ e

约

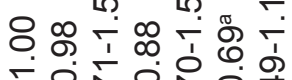

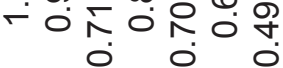

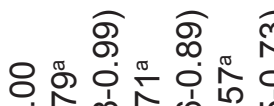

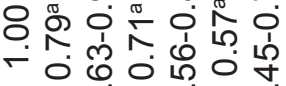

๑ @

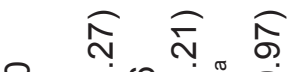

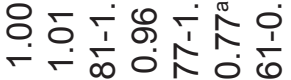

อ $@$

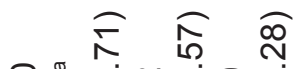

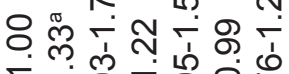

-

ఠิ

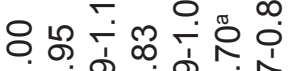

- Oर० ơ

¿ $@$

등

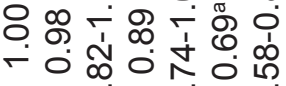

๑ $巳$

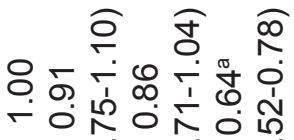

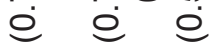

तु

8 눈

-
8.

$\widehat{\varnothing}$

8

$\stackrel{\circ}{0}$

0
0
0
0
0
0
0
0
0
0
0

ब.

응

อ

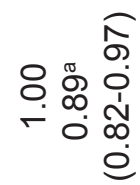

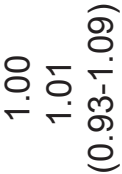

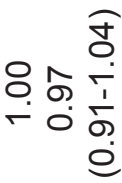

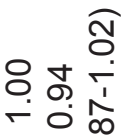

อ

৪

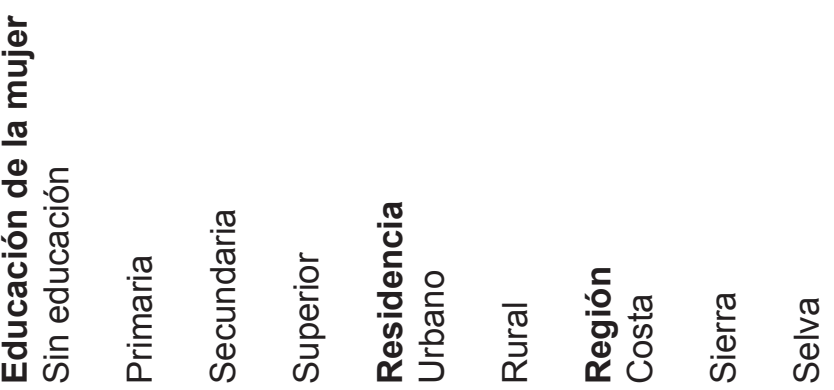

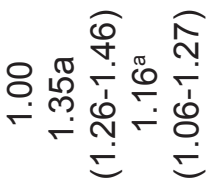

৪

$\widehat{\bar{m}} \widehat{\underline{m}}$

웅동ㄷㅇ

$\doteq \dot{0}$

क

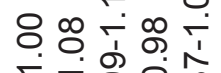

-

จิ षิ

웅영영

c 0

ล

ㅇํㅇำ 노ำ

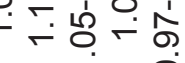

¿

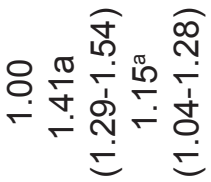

施

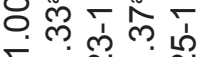

$\stackrel{\square}{=}$

is f

웅

网

$8 \stackrel{7}{2} \div$

+. 


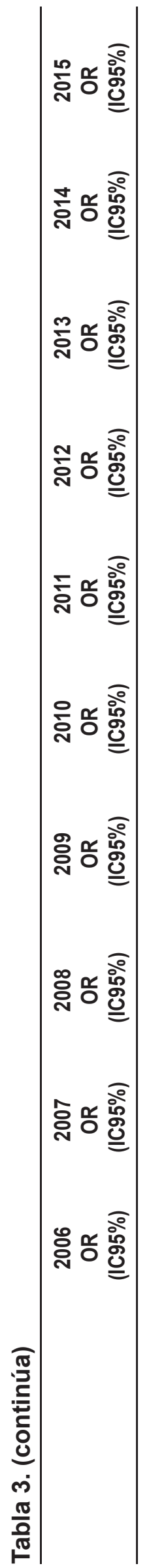

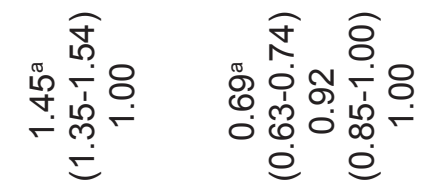

卞,

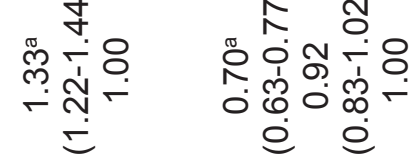

ఫิ

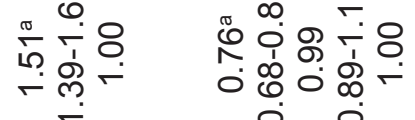

$\stackrel{1}{=}$

¿

范

б으

$=$

周 8

宁官

=

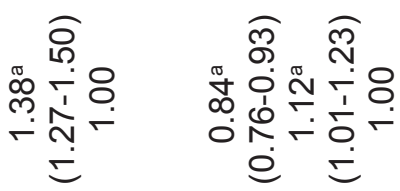

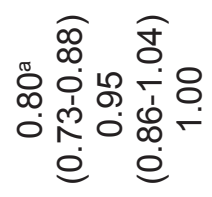

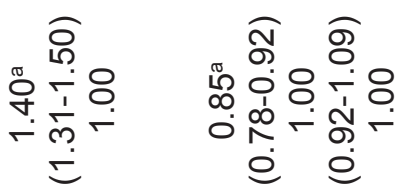

กิ

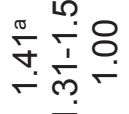

离

$=$

的-

¿

กิ

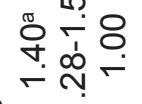

के क्ष

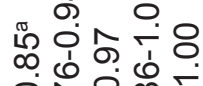

$\infty$
01
0
0
0

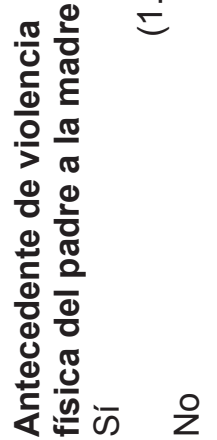

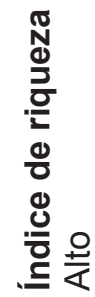
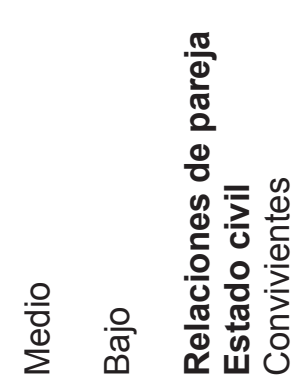

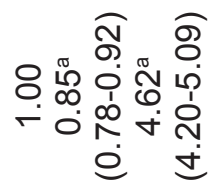

ติ

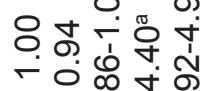

¿ ल

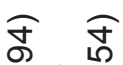

융ํำ

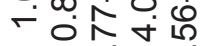

¿ ले

बำ

8000

잉ำ

¿ ल

ถู สู

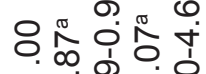

- 0 웅

()

क्

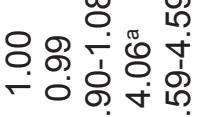

○

बิ

80000

-0
0
0

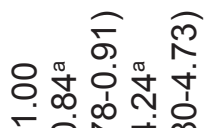

¿ ल

के

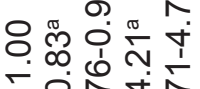

एं

চิ ฮু

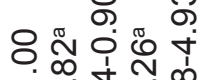

-0
0

¿ ले

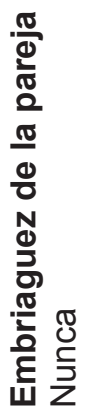

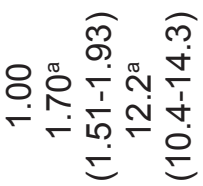

เก ส

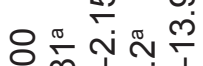

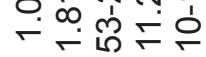

$=0$

के ซ.

هั

$=5$

จ $\widehat{\circ}$

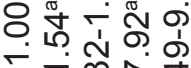

$=$

สิ

ㅇำ ำ ํํำ

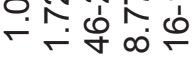

$= \pm$

点

8ㅇํำ

-

$=0$

每

8. 댇ㄷำ

$\stackrel{\sim}{\sim} \stackrel{\infty}{=}$

क़

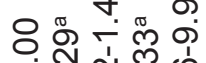

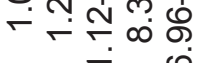

$=0$

โิ

윴ำ

-

$=0$

สิ กิ

8 乐

㠃它它客

$=\theta$

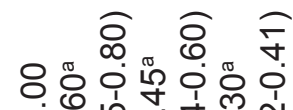

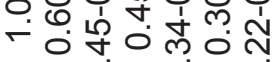

¿ @

कิ

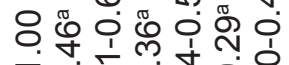

०。丶万人

○ e

ลกำ 음

응당ํำ

둔다영

¿ 0 e

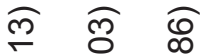

8 운

- 0 150

e $巳$

कิ তิ

8 м

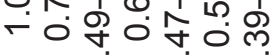

- e e

क्व $\widehat{\sigma}$

$8 \infty \frac{1}{1} \infty \begin{gathered}1 \\ 0\end{gathered}$

- 000000

จิ

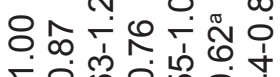

¿ e

ક્ષ శิ

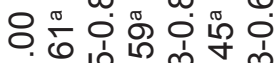

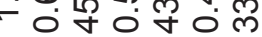

¿ 0

ฟิ ฟิ

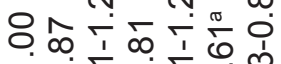

$\div 00000 \%$

¿ 0

동 ฮ

8 8.

- ○ी

○ e 


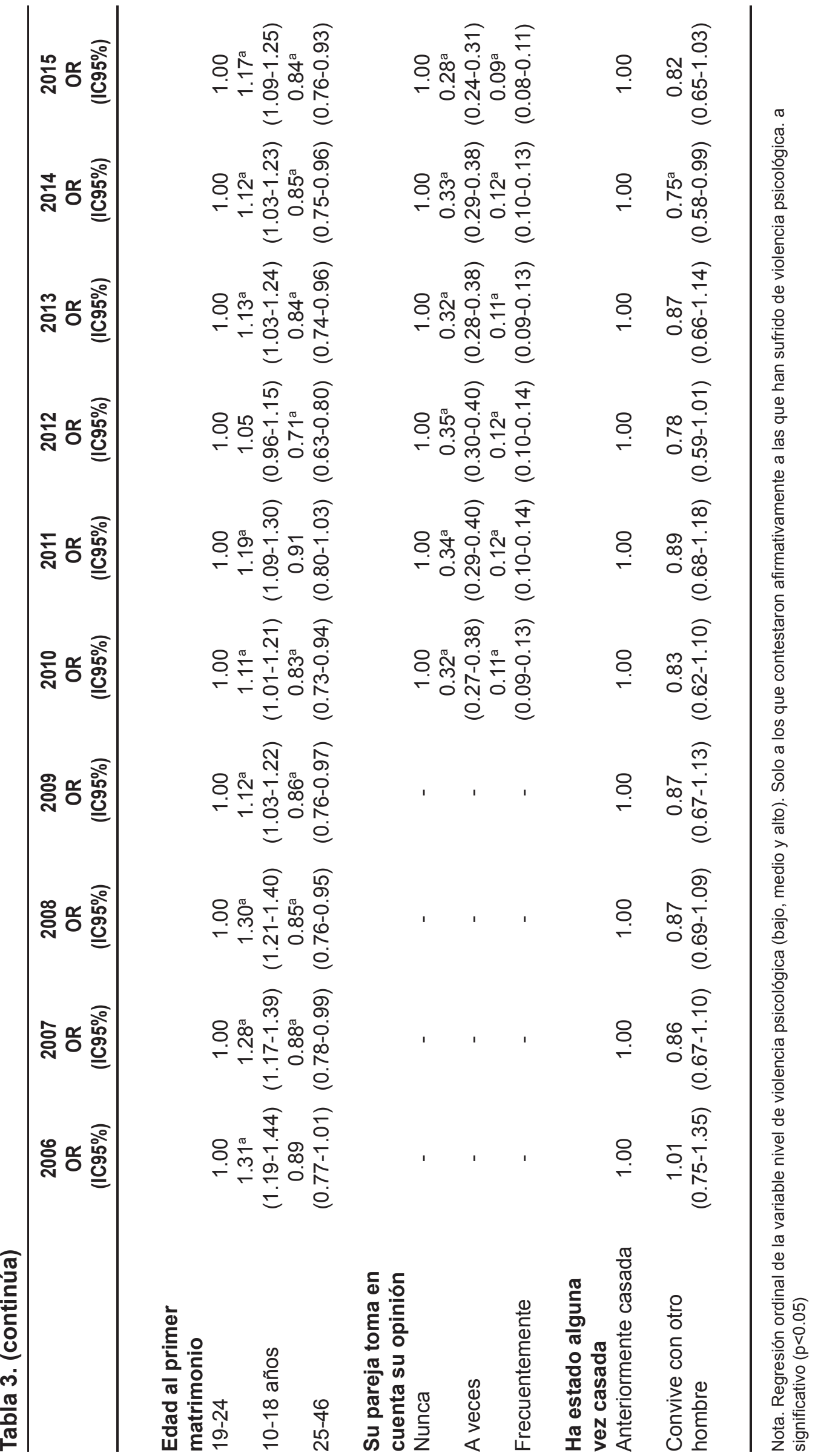




\section{DISCUSIÓN}

El porcentaje de mujeres que han sido violentadas psicológicamente por su pareja ha disminuido desde el 2006 llegando a un $65.5 \%$ en el 2015. El aumento de la violencia psicológica vinculado a factores individuales se verifica en las mujeres que vivían en la región sierra y con antecedente de violencia física. Respecto a los factores de relación de pareja: iniciar temprano un matrimonio, ser separada, tener parejas que se embriagan frecuentemente están asociados con este tipo de violencia. Del mismo modo, durante los últimos diez años los factores que se asocian de manera constante con el aumento de la violencia psicológica fueron: tener antecedentes de violencia física del padre a la madre, ser separada y la embriaguez frecuentemente de la pareja.

Las mujeres que viven en la región sierra están propensas a presentar violencia psicológica por parte de su pareja. Estudios muestran un similar hallazgo $(9,20)$. Esto podría deberse a que en estas zonas aún existe la creencia de que la mujer tiene que vivir sometida al marido y que sólo él puede proveerle económicamente. En muchos casos la mujer soporta el maltrato por el temor al abandono y la desatención del hogar (21). Además en algunos de estos lugares no llegan los servicios públicos de salud, ni los medios de comunicación por tanto las necesidades de salud vinculadas a la violencia no son atendidas adecuadamente (22).

Las mujeres con un antecedente de violencia física del padre contra su madre es un factor de riesgo para la violencia psicológica (11). La violencia psicológica puede ser aprendida de manera vicaria por los hijos. Es decir, si la niña observa que su padre insulta o agrede a su madre y esta no hace nada frente, cuando esta tenga pareja pudiera permitir lo mismo, ya que lo consideraría como algo normal y aceptable en una relación porque así lo aprendió $(11,12)$.

Ser separada es un factor asociado a la violencia psicológica. Un estudio realizado en el Perú reporta un similar hallazgo (10). El hecho de finalizar una relación no garantiza el fin de la violencia, incluso puede agravarla por ser un hecho estresante para el hombre. Este pudiera no soporta perder el control que tiene sobre la mujer generando nuevas situaciones de violencia (13).
Otro factor asociado a la violencia psicológica fue la embriaguez frecuente por parte de la pareja (14). El consumo frecuente del alcohol afecta al sistema nervioso central trayendo como consecuencia la desinhibición de la conducta impidiendo cualquier acto de control sobre los impulsos. Está situación da lugar a las agresiones verbales, físicas y psicológicas por parte de la pareja (23).

Las mujeres que se casaron por primera vez en edad adolescente están propensas a la violencia psicológica (24). Esto puede deberse a que la mayoría de matrimonios a edad temprana suelen darse por arreglo de los padres buscando la mejora económica para salir de pobreza. También pueden ser motivados por un embarazo con la finalidad de no defraudar a la familia o para escapar de la violencia en el hogar. Esto trae como consecuencia situaciones de sometimiento al marido, lo cual le impide la toma de decisiones y limita su desarrollo personal $(25,26)$.

Los factores protectores individuales frente a la violencia psicológica en las mujeres fueron el índice de riqueza alto y el nivel educativo superior. Estudios similares reportan que las mujeres con más de diez años de escolaridad tienen una menor incidencia de presentar violencia por parte de su pareja $(8,9)$. Esto podría deberse a que las mujeres con mayores recursos económicos cuentan con mayor acceso a la educación e información sobre los recursos para contrarestar la violencia contra la mujer. Asimismo, no contar con recursos económicos suficientes que permiten ser independientes haría que el hombre use su poder para maltratarla considerando que es el único proveedor (8).

Respecto a los factores de protección en relación con la pareja fueron ser casada, casarse después de los 25 años y el tomar en cuenta su opinión frecuentemente. Es importante reconocer que las parejas casadas mantienen un compromiso formalmente reconocido que se trata de mantener. Por lo que ejercer violencia favorecería la ruptura del vínculo $(10,27)$. Asimismo una mujer que inicia su vida conyugal a una edad madura tiene menos probabilidad de sufrir violencia debido a que muchas de ellas poseen mayor acceso a un trabajo remunerado, niveles de educación altos y 
por ende mayores niveles de autonomía económica (9). Respecto a la toma de decisiones, si el hombre es el único que tiene la decisión del hogar, la mujer tiene mayor riesgo de sufrir violencia psicológica. Sin embargo el mismo disminuye si en la toma de decisiones en el hogar participan ambos a través de una comunicación asertiva (28).

El ajuste de los modelos como la capacidad discriminante fueron aceptables. Es decir, ambos modelos tienen buena capacidad discriminatoria de la violencia psicológica. Una explicación relativa se vincula con la elección de las variables predictoras a partir de la teoría ecológica (16-18), que considera factores individuales y relaciones de parejas que impactan en la violencia psicológica. Por otro lado, se debe tener en cuenta que en otra investigación publicada el área bajo la curva fue mayor que la estimada en el presente estudio (0.78) y que estas diferencias puedan deberse a la selección de las variables predictoras (29).

Entre las limitaciones del estudio se deben considerar que la información relativa a la pareja proviene exclusivamente de respuestas de las encuestadas. Por otro lado, para una consideración global del fenómeno serían necesario tomar en cuenta otras variables como factores de relaciones con otros (familia, amigos $\mathrm{y}$ otros). Sin embargo, esta información no está disponible por las características de la ENDES. Entre las fortalezas destacan el contar con una muestra representativa de mujeres peruanas y el análisis del fenómeno en un periodo de diez años.

\section{CONCLUSIONES}

Durante los últimos diez años existen factores que se asocian en modo constante al aumento de la violencia psicológica (tener antecedentes de violencia física del padre a la madre, ser separada y la embriaguez frecuente de la pareja). Por otro lado, los factores individuales (vivir en región sierra y tener antecedentes de violencia física) y los factores de relaciones de pareja (ser separada, que el compañero se embriague frecuentemente y casarse en edad adolescente) están asociados a un aumento de ser víctimas de violencia psicológica. Los factores de relación de pareja son los que inciden más en la violencia psicológica. Del mismo modo ser casada, tener un índice de riqueza alto y tener educación superior tanto en la mujer como en el hombre ayudan a prevenir que este tipo de violencia se manifieste.

Se recomienda realizar estudios mixtos donde se incluyan entrevistas a profundidad a las mujeres y a sus parejas con el fin de obtener más detalles de los factores involucrados en la violencia psicológica. Asimismo se recomienda considerar la detección temprana del consumo abusivo de alcohol como factor desencadenante de la violencia psicológica. Este elemento se debería tener en cuenta en el diseño de políticas públicas de salud relativas a la disminución de la violencia contra las mujeres. De igual modo se deben considerar los factores protectores para fortalecer los programas de prevención de la violencia doméstica.

\section{REFERENCIAS BIBLIOGRÁFICAS} Rodríguez, L. Definición,
fundamentación y clasificación de la violencia;2013 disponible en: http://www.msc.es/ciudadanos/viole ncia/docs.

2. Martínez, M. López, A. Montesinos, A. Teseirio, M. Violencia intrafamiliar y trastornos psicológicos en niños y adolescentes del área de salud de Versalles, Matanzas. Revista Médica Electrónica. 2015;37(3):91-110.

3. Organización Mundial de la Salud. Violencia contra la mujer; 2016. disponble en:

http://www.who.int/mediacentre/fact sheets/fs239/es/
4. Blázquez, M. Moreno, J. García, M. Sánchez, B. Revisión teórica del maltrato psicológico en la violencia conyugal. Psicología y Salud. 2010;20(1):65-75.

5. Instituto Nacional de Estadística e Informática. Encuesta Demográfica y de Salud Familiar 2016. Lima Perú: INEI; 2016.Disponible en: https://www.inei.gob.pe.

6. Ruiz, M. García, E. Ruiz, Y. Valdivia, G. Tippe, L. Córdova, L. Palacios, C. Factores de riesgo de violencia de género en adolescentes de educación secundaria, Manchay. Revista Cuidado y Salud/Kawsayninchis. 2015;2(1):156-163.
7. Martínez, M. López, A. Montesinos, A. Teseirio, M. Violencia intrafamiliar $y$ trastornos psicológicos en niños y adolescentes del área de salud de Versalles, Matanzas. Revista Médica Electrónica. 2015;37(3):91-110.

8. González, M. Acceso a la justicia y conflictos intrafamiliares. Marginación y pobreza en el ámbito judicial. La Plata: Imás, 2013:200.

9. Jaen, C. Rivera,S. Amorin de Castro, E. Rivera, L. Violencia de Pareja en Mujeres: Prevalencia y Factores Asociados. UNAM Facultad de Psicología. 2015;5(3):2224-2239. 
10. Caballero, J. Alfaro, M. Nuñez, Y. Torres, H. Violencia psicológica contra la mujer por su pareja en el Perú, 4004-2007. (Maestría en Epidemiología). Universidad Nacional Mayor de San Marcos, Lima, Perú; 2009.

11. Guedes, A. García, C; Bott, S. Violencia contra las mujeres en Latinoamérica y el Caribe. Revista Foreign Affairs Latinoamérica. 2014;14(1):41-48.

12. Tenorio, M. Adolescencia, pareja y violencia familiar. Temát. psicol. 2011;7(1)

13. Zaldívar, A. etal. Las mujeres separadas de cara a la violencia de sus exparejas. Rumbo a su caracterización. Ciencias UAT. 2015;10(1):83-92.

14. Giménez, C. Rodríguez, M. Hernández, M. Relación entre el consumo abusivo de alcohol y la violencia ejercida por el hombre contra su pareja en la unidad de valoración integral de violencia de género (UVIVG) de Sevilla. 2014;20(4):151-169.

15. Ruiu. M. Violencia Familiar. Violencia Contra La Mujer en las Relaciones de Pareja. Revista de IN IURE. 2013;1:82-105.

16. De Alencar, R. Rodrigues, L. Violencia de Género en la Pareja: Una Revisión Teórica. Universidad Autónoma de Barcelona, España. 2012;43(1):116-126.
17. Heise LL. Violence against women: an integrated, ecológica framework. Violence Against Women. 1998;4(3):262-90.

18. Bronfenbrenner, U. Ecology of the family as a context for human development: research perspectives. Developmental Psychology. 1986;22(6):723-42.

19. Instituto Nacional de Estadística e Informática. Encuesta Demográfica y de Salud Familiar 2016. Lima Perú: INEI; 2016. Disponible en: http://iinei.inei.gob.pe/microdatos/

20. Darcout, A. Caracterización de las mujeres que demandan interconsulta de psicología por violencia. Revista Finlay. 2017;7(1):5-16.

21. Larrauiri, E. ¿Porque retiran las mujeres maltratadas las denuncias? Revista de derecho penal y criminología. 2003;12:271-307.

22. Ramírez, C. Santiago, R. Hernández, R. La percepción del apoyo social en mujeres con experiencia de violencia conyugal. Salud mental. 2005;28(4):66-73.

23. Rivera, L. et al. Prevalence and determinants of male partner violence against Mexican women: A population-based study.salud pública de méxico. 2004;46(2).

24. Sebastián, J. et al. La Violencia en las Relaciones de Pareja de los Jóvenes. ¿ Hacia Dónde Caminamos? Violence in Young Couples. What is the Way Ahead?. Clínica. 2010;1(2):71-83.
25. Amurrio, M. Larrinaga, A. Usategui, E. Del Valle, A. Violencia de género en las relaciones de pareja de adolescentes y jóvenes de Bilbao. Revista de servicios sociales. 2010;47:121-134.

26. Mendoza, L. Claros, D. Mendoza, L. et al. Matrimonio infantil: Un problema social, económico y de salud pública. Rev Chil Obstet Ginecol. 2016; 81(3):254-261.

27. Moreno, F. La violencia en la pareja. Rev Panam Salud Pública. 1999;5(4/5):245-258.

28. Casique, I. Factores de empoderamiento y protección de las mujeres contra la violencia. Revista Mexicana de Sociología. 2010;72(1):37-71.

29. Abed, H. Abu-Saada, Mahmoud K. Okasha, and Haroun M. Bhar Al-Azhar University - Gaza, Palestine. Multinomial Analysis of the Trend in Prevalence of Violent Incidents against Women in Palestine from 2005 to 2011. Arab Journal for Statistical Sciences and their Applications in Social and Human Sciences [AJSS]. 2015;2(1): 69-96. 


\section{What factors are associated with domestic psychological violence? Analysis of the last decade of ENDES}

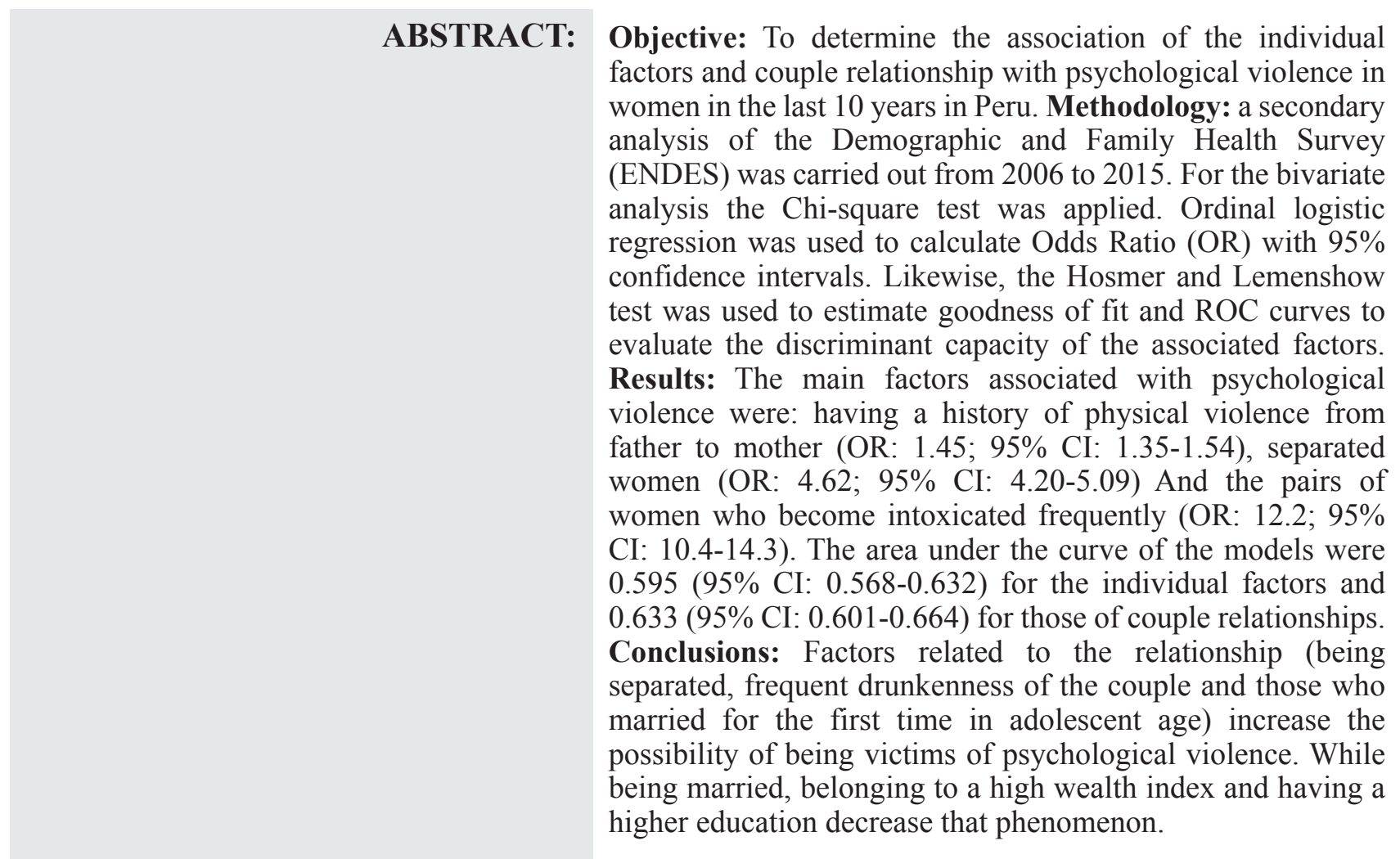

KEY WORDS: Intimate Partner; Violence Psychological abuse; Women 